\title{
Alterations of protein 4.1 family members in ependymomas: a study of 84 cases
}

\author{
Veena Rajaram ${ }^{1}$, David H Gutmann², Srinivas K Prasad ${ }^{3}$, David B Mansur ${ }^{4}$ and Arie Perry ${ }^{1}$ \\ ${ }^{1}$ Department of Pathology, Washington University School of Medicine, St Louis, MO, USA; ${ }^{2}$ Department of \\ Neurology, Washington University School of Medicine, St Louis, MO, USA; ${ }^{3}$ Department of Neurosurgery, \\ Washington University School of Medicine, St Louis, MO, USA and ${ }^{4}$ Department of Radiation-Oncology, \\ Washington University School of Medicine, St Louis, MO, USA
}

\begin{abstract}
Ependymomas are common pediatric and adult CNS malignancies with a wide biologic spectrum that is often hard to predict using classic prognostic variables. The molecular pathogenesis is also poorly understood and few reproducible genetic alterations have been identified. The most common genetic alteration has been the loss of the Protein 4.1 family member, NF2, predominantly in spinal ependymomas. In contrast, a pilot study suggested that $4.1 B$ deletions might be more common in intracranial ependymomas. These findings prompted us to study Protein 4.1 family members (NF2, 4.1B, 4.1R, 4.1G) in a larger cohort of 84 ependymomas (51 intracranial and 33 spinal; 11 WHO grade I, 43 grade II, 30 grade III). Fluorescence in situ hybridization was performed using NF2, 4.1B, 4.1R and 4.1G probes and immunohistochemical staining was performed in a subset using merlin, Protein 4.1B and Protein 4.1R antibodies. Additionally, frozen tissue from nine ependymomas (four intracranial and five spinal) was obtained for Western blot analysis for merlin, 4.1B and 4.1R expression. The majority of cases harbored one or more detectable genetic alterations, but we found that 4.1B gene deletions and 4.1R loss of expression were statistically more common in the pediatric vs adult, intracranial vs spinal, and grade III vs grade I/II subsets ( $P$-values of 0.038 to $<0.001$ ). Also, $4.1 G$ deletions were seen in 11/27 (41\%) patients who either died of disease or had residual/recurrent tumor vs $5 / 41$ patients with no evidence of disease at last follow-up $(P=\mathbf{0 . 0 0 9})$. We conclude that alterations of Protein 4.1 family members are common in ependymal tumors and that specific alterations are associated with distinct clinicopathologic subsets.
\end{abstract}

Modern Pathology (2005) 18, 991-997. doi:10.1038/modpathol.3800390; Published online 25 February 2005

Keywords: ependymoma; NF2; pediatric; prognosis; protein 4.1; tumor genetics

Ependymomas are malignant brain and spinal cord gliomas, primarily affecting children and young adults. They comprise $3-9 \%$ of all primary central nervous system (CNS) tumors $(6-12 \%$ in children, and $30 \%$ in patients $<3$ years of age). Established prognostic variables include age, tumor location, and extent of surgical resection. Histological grading has been less consistent, showing significant associations with clinical behavior mainly in the larger series with long follow-up. The molecular pathogenesis of ependymomas has also remained elusive and alterations common to other gliomas, specifically those of the astrocytoma subtype are not common. ${ }^{1-8}$ In contrast, there is at least some genetic overlap

Correspondence: Dr A Perry, MD, Division of Neuropathology, Campus Box 8118, Washington University School of Medicine, St Louis, MO 63110-1093, USA.

E-mail: aperry@wustl.edu

Received 12 November 2004; revised 12 January 2005; accepted 13 January 2005; published online 25 February 2005 with another primary CNS tumor, the meningioma. The most consistent genetic changes in ependymoma have been chromosome 22 deletions in $30-70 \%$ of tumors, ${ }^{9-11}$ with inactivating mutations of the NF2 tumor suppressor gene or loss of expression of its protein product, merlin (or schwannomin), in $29-38 \%$ of spinal ependymomas. ${ }^{12-16}$ Such mutations have been rare in the intracranial counterparts.

NF2 is one of the key growth regulatory members of the cell membrane/cytoskeleton-associated Protein 4.1 superfamily, characterized by homologous FERM domains and functional roles in membrane trafficking, cell-cell adhesion, cell motility, and signal transduction. ${ }^{17,18}$ In a pilot study of 27 ependymomas, we found evidence for involvement of a second family member, $4.1 B$ on $18 \mathrm{p} 11.3$ (previously known as $D A L-1$ for 'differentially expressed in adenocarcinoma of the lung $\left.1^{\prime}\right) .{ }^{16}$ In contrast to $N F 2,4.1 B$ alterations were seen almost exclusively in the intracranial tumors, suggesting the possibility of differential involvement of Protein 
4.1 members according to tumor site. However, this trend did not reach statistical significance in our preliminary study. Also, since the majority of ependymomas had neither NF2 nor $4.1 B$ losses, other critical genetic alterations likely exist.

There are several reasons to suspect two additional Protein 4.1 family members (the erythrocyteassociated $4.1 R$ on $1 \mathrm{p} 32-33$ and the more ubiquitously expressed $4.1 G$ on 6q23) might represent candidate ependymoma tumor suppressor genes. First, both of these cytogenetic loci are commonly implicated as sites of either deletion or rearrangement in ependymomas. ${ }^{9-11,19-21}$ Secondly, both of these family members are highly expressed in the brain. ${ }^{22,23}$ Lastly, we have demonstrated a growth regulatory role for several Protein 4.1 family members in meningiomas, ${ }^{24-26}$ and preliminary studies have shown that the reintroduction of Protein 4.1R into 4.1R-negative meningioma cell lines results in growth suppression. ${ }^{27}$ Based on these observations, we decided to study the Protein 4.1 family members in a larger set of ependymomas. Our data suggest that particular alterations in Protein 4.1 gene dosage and expression are associated with specific clinicopathologic subsets of ependymoma.

\section{Materials and methods}

An ependymoma tissue microarray was created using clinically and pathologically well characterized, archival specimens from Washington University School of Medicine. We retrieved and reviewed archival slides and blocks from 84 ependymomas (51 intracranial and 33 spinal) resected between 1967 and 2002, with application of current World Health Organization (WHO) classification and grading criteria. ${ }^{1}$ Three representative regions were selected per case and $0.6-\mathrm{mm}$ cores were extracted from the corresponding donor block, yielding a final tissue microarray block containing approximately 350 tissue cores (including cores from normal lung as controls). Sections of $5 \mu \mathrm{m}$ thickness were cut and mounted onto poly-L-lysine-coated slides for fluorescence in situ hybridization (FISH) and immunohistochemistry. Immunohistochemical stains were originally performed on TMA sections, but unfortunately were not interpretable due to problems with high background. Therefore, immunohistochemistry was repeated on whole tissue sections in a subset of 52 cases.

Dual colored FISH was performed as previously reported. ${ }^{8,16,26,27}$ Sources of DNA probes are summarized in Table 1 . The tissue sections were deparaffinized and subjected to target retrieval by steam cooking in citrate buffer $(20 \mathrm{~min})$, cooling (20 min) and washing $(5 \mathrm{~min})$ followed by pepsin digestion $\left(4 \mathrm{mg} / \mathrm{ml}\right.$ at $37^{\circ} \mathrm{C}$ for $\left.30 \mathrm{~min}\right)$. The slides were washed in $2 \times$ saline-sodium citrate (SSC) for $5 \mathrm{~min}$ and air-dried. The probes were diluted in DenHyb hybridization buffer (1:25) (Insitus Laboratories, Albuquerque, NM, USA) and paired [4.1R (1p32)/1q42, BCR (22q11.2)/NF2 (22q12), CEP18/ $4.1 B$ (18p11.3), CEP6/4.1G (6q23)]. A volume of $10 \mu \mathrm{l}$ of the hybridization mix was applied to each slide, and the probe and the target DNA were simultaneously denatured at $90^{\circ} \mathrm{C}$ for $13 \mathrm{~min}$. Following overnight hybridization at $37^{\circ} \mathrm{C}$ in a humidified chamber, the slides were washed at room temperature in $50 \%$ formamide $/ 1 \times$ SSC for 5 min followed by a wash in $2 \times$ SSC for 5 min. The slides were airdried and counterstained with DAPI $(0.5 \mu \mathrm{l} / \mathrm{ml}$; Insitus Laboratories). Sections were viewed under an Olympus BX60 fluorescent microscope with appropriate filters (Olympus, Melville, NY, USA) and those showing $>90 \%$ nuclei with signals were evaluated, with 100 intact nonoverlapping nuclei scored for the number of fluorescent signals. Hybridizations were digitally photographed using a high-resolution black and white COHU chargecoupled device (CCD) camera, with a Z-stack motor programmed to capture images at sequential DAPI (1 level), fluorescein isothiocyanate (FITC) (10 levels), and rhodamine (10 levels) filter settings. Reconstruction into a single superimposed image with blue, green, and red pseudocolors was accomplished using a CytoVisionTM basic workstation (Applied Imaging, Santa Clara, CA, USA).

Immunohistochemistry was performed as previously published. ${ }^{13,16,24-27}$ Slides were deparaffinized and treated with $3 \%$ hydrogen peroxide to remove endogenous peroxidase activity. Antigen

Table 1 Sources of DNA probes used for FISH

\begin{tabular}{|c|c|c|}
\hline Probe & Clone/product & Source \\
\hline $4.1 R(1 \mathrm{p} 32)$ (green) & PAC11c11 & John Conboy, Lawrence Berkeley National Laboratory, Berkeley, CA, USA \\
\hline $1 \mathrm{q} 42$ (red) & RP11- 184E11 & Genome Sequencing Center, Washington University, St Louis, MO, USA \\
\hline$N F 2(22 q 12)($ red) & Cosmids n 3022 and n24f20 & $\begin{array}{l}\text { Mia MacCollin, Massachusetts, Boston, MA and the UK Human Genome } \\
\text { Mapping Project Resource Center (http://www.hgmp.mrc.ac.uk) }\end{array}$ \\
\hline$B C R$ (green) & LSI 22q11.2 & Vysis, Downers Grove, IL, USA \\
\hline $4.1 B(18 \mathrm{p} 11.3)$ (green) & P1-210-H5 & $\begin{array}{l}\text { Irene Newsham, Henry Ford Hospital, Detroit, MI, USA and Human P1 Library, } \\
\text { Genome Systems Inc., St Louis, MO, USA }\end{array}$ \\
\hline CEP18 (red) (D18Z1) & Alpha satellite DNA & Vysis, Downers Grove, IL, USA \\
\hline CEP6 (green) (D6Z1) & Alpha satellite DNA & Vysis, Downers Grove, IL, USA \\
\hline $4.1 \mathrm{G}(6 \mathrm{q} 23)(\mathrm{red})$ & RP11-006O11 & Genome Sequencing Center, Washington University, St Louis, MO, USA \\
\hline
\end{tabular}


retrieval was performed by placing slides in boiling $10 \mathrm{mM}$ sodium citrate for $10 \mathrm{~min}$. The sections were blocked with $1 \%$ bovine serum albumin (BSA) and incubated with the following primary antibodies at $4{ }^{\circ} \mathrm{C}$ : affinity-purified rabbit polyclonal antibodies against merlin (WA30, 1:500), Protein 4.1B (3A1, 1:500), and Protein 4.1R (Santa Cruz Biotechnology Inc., Santa Cruz, CA, 1:6000). A reliable Protein 4.1G antibody suitable for immunohistochemical analysis was not available. Secondary anti-rabbit biotinylated antibodies (Sigma) were applied at a 1:200 dilution and the slides developed with 3,3'-diamino-benzidine (DAB) chromogen. Mouse choroid plexus was used as a positive control and omission of the primary antibody served as the negative control for staining. Additional internal positive controls included erythrocytes for Protein 4.1R and intratumoral blood vessels for Proteins $4.1 \mathrm{~B}$ and 4.1R.

For Western blot analysis, frozen tissue from nine ependymomas (four intracranial, five spinal) were homogenized in NP40 lysis buffer containing protease inhibitors. The protein concentration was determined by the Biorad method (Biorad Laboratories, Hercules, CA, USA). Electrophoresis was performed using either 100 or $50 \mu \mathrm{g}$ of each sample loaded on $10 \%$ SDS-PAGE gels. Proteins were transferred onto Immobilon membranes (Millipore, Bedford, MA, USA) for Western blotting with primary antibodies (merlin, Protein 4.B and Protein 4.1R). Western blots were developed using horseradish peroxidase-conjugated secondary antibodies (1:200 000) and ECL chemiluminescence (Amersham Biosciences).

Associations between frequencies of genetic alterations, tumor location (intracranial vs spinal) and patient age (pediatric or adult) were evaluated based on the Fisher's exact test. Reported $P$-values of $<0.05$ were considered statistically significant.

\section{Results}

The study cohort consisted of 51 intracranial tumors; 41 posterior fossa ependymomas from patients ranging in age from 7 months to 72 (median 7) years and 10 supratentorial ependymomas from patients ranging in age from 4 to 35 (median 13) years. There were 33 spinal ependymomas from patients ranging from 13 to 69 (median 41) years of age. Stratified by age, there were 40 pediatric (eight supratentorial, 28 posterior fossa, and four spinal) and 44 adult (two supratentorial, 13 posterior fossa and 29 spinal) tumors. The age range for the pediatric group was 7 months to 18 years (mean $=6$ 6 years, median $=4$ years) and the adults ranged from 22 to 72 years $($ mean $=45$, median $=38)$. Histologically, there were 30 WHO grade III anaplastic ependymomas (eight supratentorial, 21 posterior fossa, one cervico-medullary), 43 WHO grade II ependymomas (two supratentorial, 19 posterior fossa, 22 spinal) and 11 WHO grade I myxopapillary ependymomas (10 spinal, one metastasis) (Figure 1).

FISH results were interpretable for 47-49 of 51 IC tumors and 31-32 of 33 spinal tumors depending on the gene tested. Immunohistochemical results were interpretable for all 32 intracranial tumors and 20 spinal tumors tested using whole tissue sections. Representative cases are illustrated in Figure 1. The FISH and immunohistochemistry data in relation to patient age, tumor site, and histologic grade are summarized in Figures 2 and 3. By FISH (Figures 2a and $3 \mathrm{a}), 80 \%$ of the intracranial tumors and $66 \%$ of the spinal tumors showed deletion of at least one of the Protein 4.1 family member genes. Although there were slightly more NF2 deletions in spinal versus intracranial tumors, these differences did not reach statistical significance. In contrast, $4.1 B$ deletions were statistically significantly more common in pediatric than adult (62 vs $19 \% ; P<0.001$ ), intracranial than spinal (49 vs $25 \%$; $P=0.038$ ), and grade III than either grade II alone (73 vs 45\%; $P=0.003$ ) or grades I and II combined (73 vs $29 \%$; $P<0.001) .4 .1 R$ and $4.1 G$ deletions were less common and did not differ significantly in subsets stratified according to patient age, tumor site, or histologic grade. Polysomies were seen in roughly $10 \%$ of all cases and did not have any statistically significant associations with specific clinicopathologic subsets.

By immunohistochemistry, losses of Protein 4.1R expression were common (Figures $2 \mathrm{~b}$ and $3 \mathrm{~b}$ ). These losses were statistically associated with young age (pediatric: $93 \%$ vs adult: $48 \%$; $P<0.001$ ), intracranial location (intracranial: $88 \%$ vs spinal: $47 \%$; $P=0.003$ ), and high-grade tumor (III: $95 \%$ vs II: $63 \% ; P=0.022$ or III: $95 \%$ vs I/II: $59 \% ; P=0.007$ ). Expression levels of merlin and Protein 4.1B did not differ significantly among these subsets.

In a selected series of ependymomas in which sufficient frozen tumor was available, Western blot analysis showed losses of Protein 4.1R in all nine ependymomas examined (Figure 4). Protein 4.1B loss was seen in three of four intracranial tumors and one of five spinal cord tumor. Loss of merlin expression was found in two of five spinal cord tumors, with retained expression in all four intracranial cases.

Clinical follow-up was available for 43 of 51 intracranial tumors for a median of 29 months (range 4-242 months, mean $=53$ months) and for 29 of 33 spinal tumors for a median of 27 months (range 2150 months, mean $=44$ months). There were 15 patients who had died of their disease (14 intracranial, one spinal), 14 alive with recurrences or residual disease (nine intracranial, five spinal), and 43 with no evidence of disease (19 intracranial, 24 spinal). Only one genetic alteration, $4.1 G$ deletion, was statistically associated with clinical outcome, in that it was encountered in $41 \%$ of patients with death, recurrence, or residual disease vs $12 \%$ of patients with no evidence of disease $(P=0.009)$. 

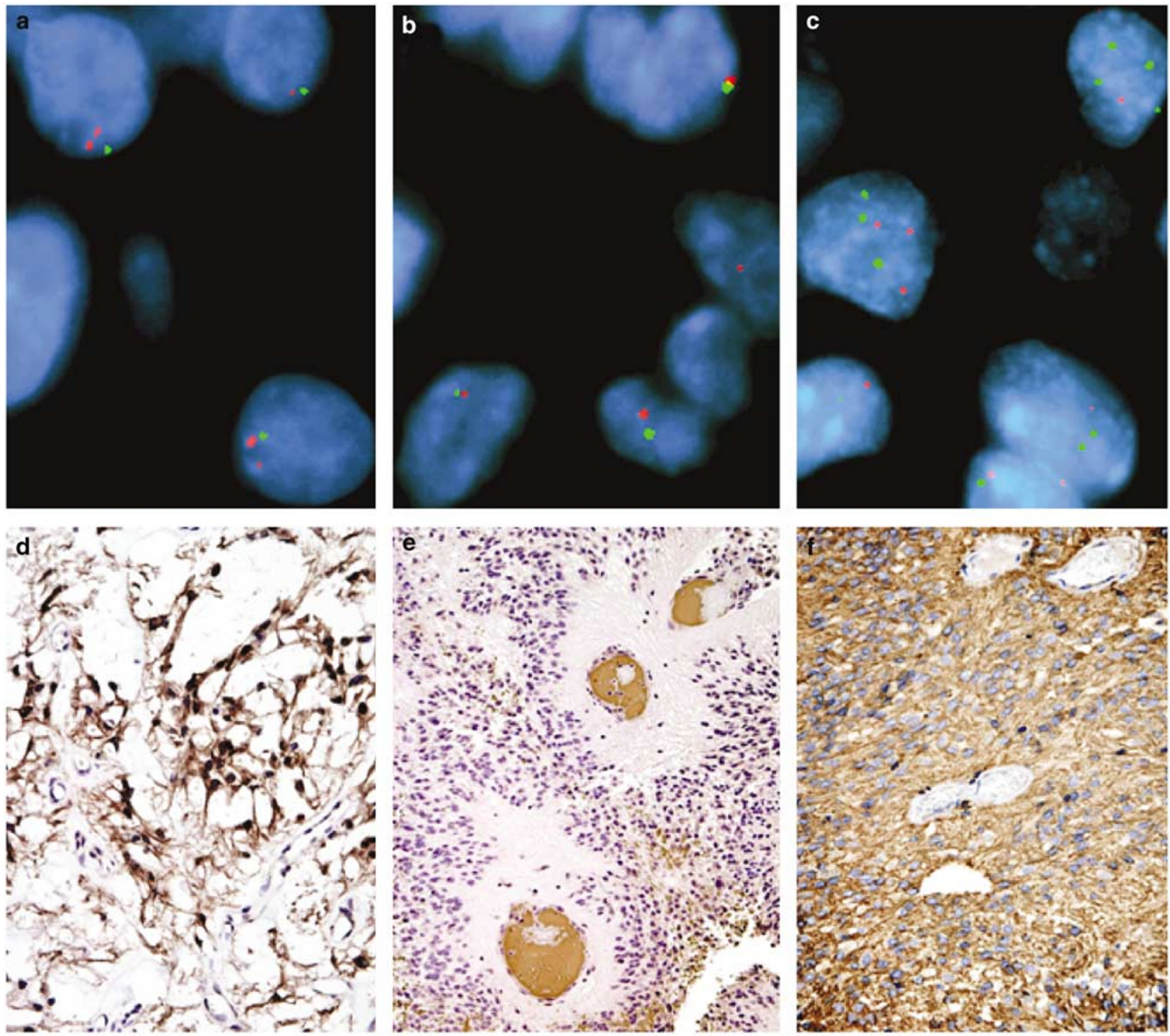

Figure 1 Representative FISH and immunohistochemistry images. (a) Deletion of $4.1 B$ gene with one green 4.1B and two red CEP18 signals in most nuclei. (b) Chromosome 22q deletion with only one red NF2 and one green BCR signals in most nuclei. (c) Polysomy 1 with $>2$ green 4.1R and >2 red 1q42 signals in a subset of nuclei. (d) Myxopapillary ependymoma with retained Protein 4.1R expression. (e) Anaplastic ependymoma with loss of Protein 4.1R expression, with intravascular red cells providing an internal positive control. (f) Retained Protein 4.1B expression in a conventional ependymoma.

\section{Discussion}

Although our understanding of ependymoma genetics remains limited, a growing body of literature supports differing molecular mechanisms of tumor pathogenesis for adult, intracranial and spinal ependymomas. ${ }^{28}$ Our findings further support this notion, demonstrating statistically significant associations for specific Protein 4.1 alterations within distinct clinicopathologic subsets of ependymoma. Specifically, we found that $4.1 B$ (18p11.3) deletions and losses of Protein 4.1R expression were each more common in the pediatric, intracranial, and/or anaplastic (WHO grade III) ependymoma subsets. Also, $4.1 G$ (6q23) deletions were associated with the more aggressive clinical disease, encountered mostly in patients that either died of their tumor or had residual/recurrent tumor at last follow-up. Losses of chromosome $6 q$ have often been implicated in studies of ependymomas in the past and as in our cases, have been found to be particularly common in pediatric ependymomas. ${ }^{19}$ However, specific associations between this alteration and distinct clinicopathologic subsets had not been thoroughly explored previously. The precise pathogenic roles for $4.1 G$ and other Protein 4.1 family members in ependymoma and potential mechanisms of inactivation remain to be elucidated. Given the fact that deletions at the DNA level often did not correlate well with losses of the protein products in 


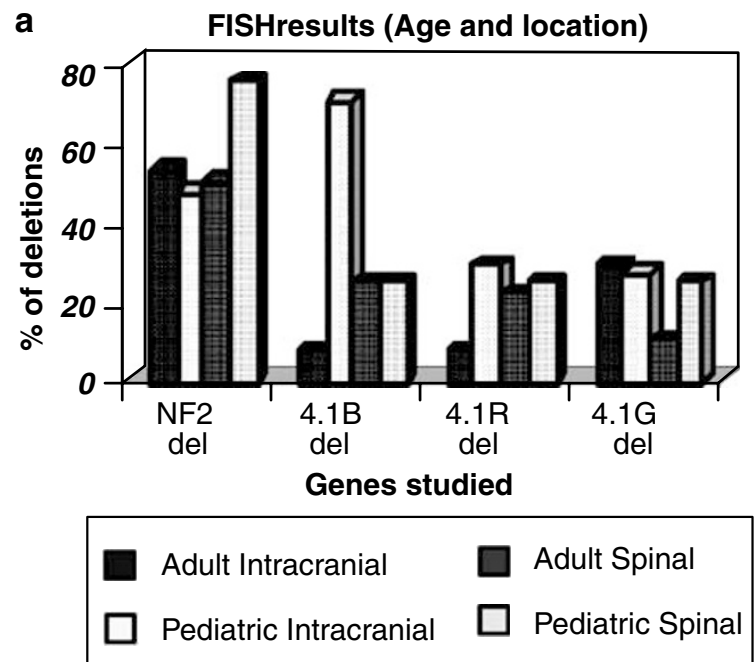

b

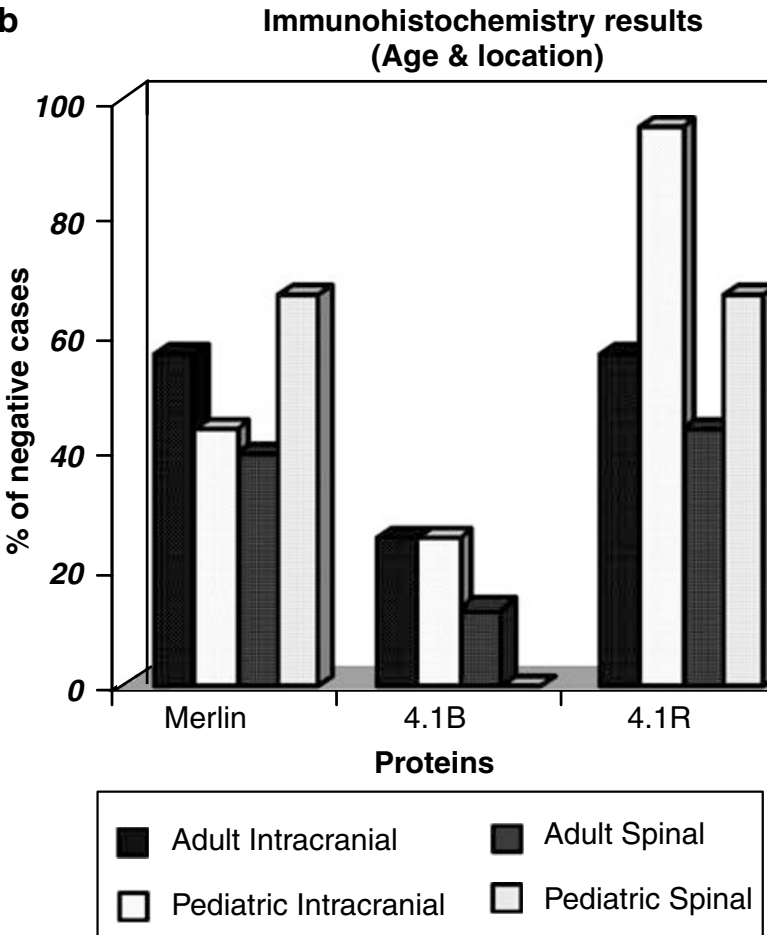

Figure 2 FISH (a) and immunohistochemical (b) detection of gene and protein losses in relation to tumor location and patient age.

our series, it is likely that other candidate genes at these cytogenetic sites are more relevant than the ones we chose to study. Nevertheless, the potential for an independent genetic marker of prognosis at $6 q 23$ could be of great clinical benefit, given the relatively poor predictability of ependymoma biology using histology alone. This association should therefore be explored further and confirmed in an independent patient cohort. Similarly, losses of Protein 4.1R protein expression were considerably more common than $4.1 R$ gene deletions detected by FISH. This suggests the possibility of other mechanisms of inactivation, such as mitotic

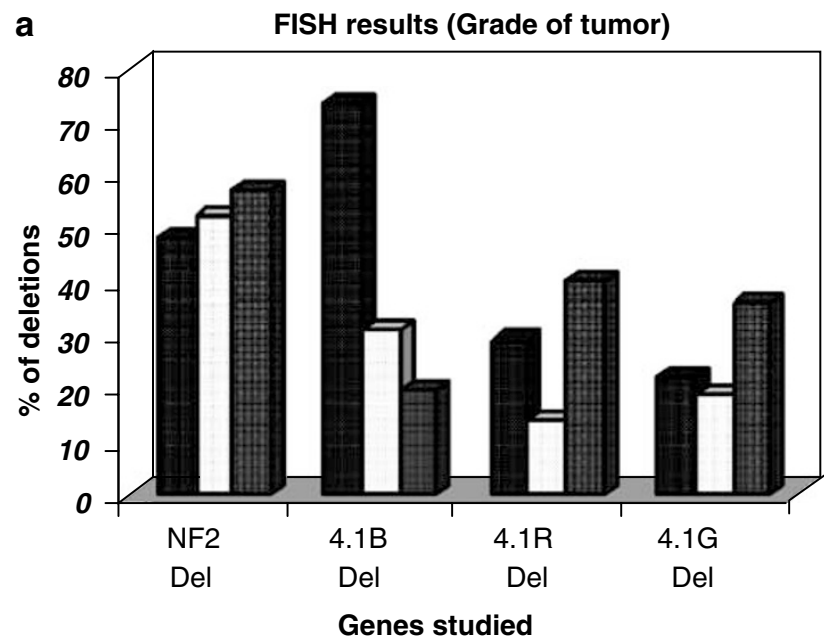

Anaplastic $\square$ Myxopapillary

Conventional

b Immunohistochemistry results (Grade of tumor)

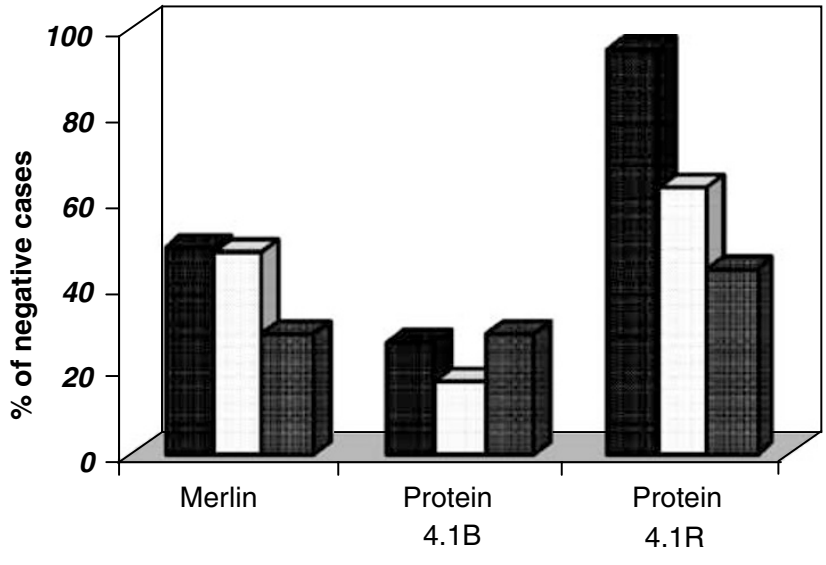

Proteins studied

Anaplastic $\square$ Myxopapillary

Conventional

Figure 3 FISH (a) and immunohistochemical (b) detection of gene and protein losses in relation to tumor grade.

recombination or hypermethylation of CpG islands. Additional studies will be needed to clarify this issue.

In terms of associations with tumor location, we found that similar to our prior study, $4.1 B$ deletions were more common in intracranial than spinal ependymomas. ${ }^{16}$ Whereas this difference did not reach statistical significance previously, it did in the current series likely due to the larger numbers of tumors utilized. This trend remained true on Western blot, though those numbers were small. Surprisingly, we did not find a predilection for NF2 deletions or merlin losses in the spinal tumors, as 


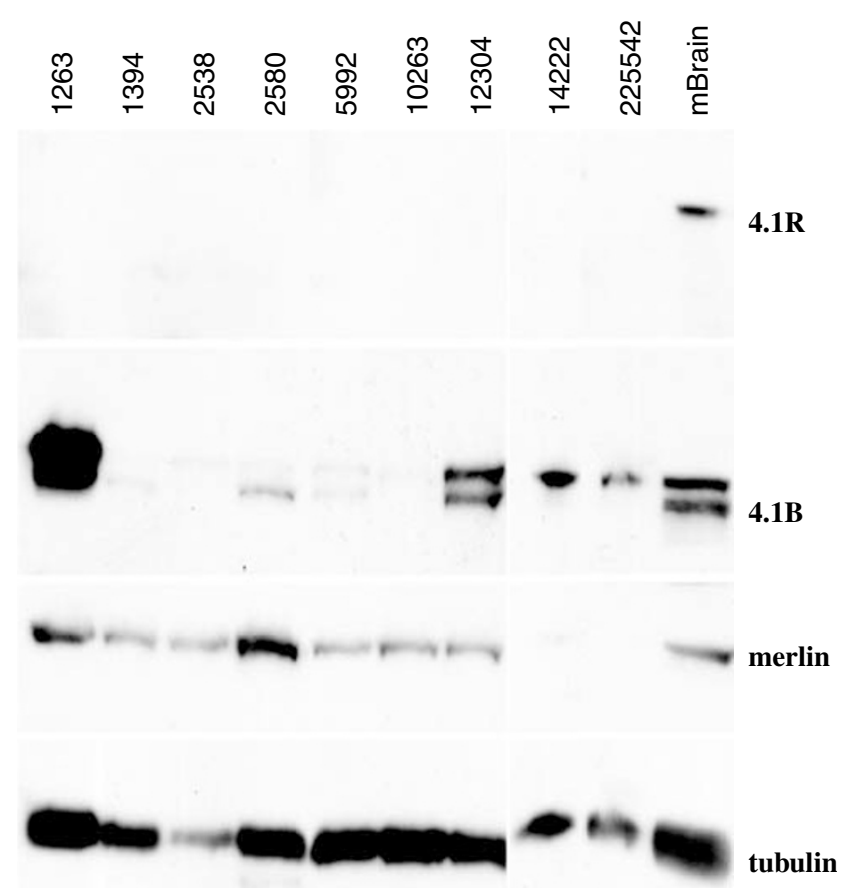

Figure 4 Western blot analysis of ependymoma samples. A nonneoplastic brain control specimen is seen in the far right lane.

has been previously reported. ${ }^{12-16}$ At the DNA level, this could be explained by the fact that intracranial ependymomas also harbor chromosome 22 deletions, particularly in pediatric cases. It is suspected that another tumor suppressor on chromosome $22 \mathrm{q}$ besides NF2 is involved in such cases, though a specific candidate has yet to be identified. At the protein level, the lack of association with spinal localization is more puzzling. The interpretation of merlin immunohistochemistry in paraffin-embedded tissue can be challenging and it is possible that this factor contributed to this apparent discrepancy in our study. In comparison, Western blot analysis revealed two of five (40\%) spinal cases with merlin loss, with all four of the intracranial counterparts retaining protein expression. Therefore, our Western blot data are consistent with the findings previously reported in the literature, though the numbers examined are too small for statistical analysis.

We conclude that DNA and protein alterations of Protein 4.1 family members are common in ependymomas. Specific alterations are statistically associated with distinct clinicopathologic features, such as patient age, tumor location, histologic grade, and/or biologic behavior. Additional studies are warranted to elucidate the pathogenic roles of these candidate genes, mechanisms of inactivation, prognostic utility of individual biomarkers, and the potential involvement of other candidate genes in close cytogenetic proximity.

\section{Acknowledgements}

We are grateful to Dr Mark Watson from the Department of Pathology and Immunology at Washington University for his help in constructing the ependymoma tissue microarray. The microarray was created by the Alvin J Siteman Cancer Center Tissue Procurement Core Facility at Washington University, St Louis, MO.

\section{References}

1 Wiestler OD, Schiffer D, Coons SW, et al. Ependymoma. In: Kleihues P, Cavenee WK (eds). World Health Organization Classification of Tumours. Pathology and Genetics of Tumours of the Nervous System. IARC Press: Lyon, 2000, pp 72-82.

2 Schiffer D, Chio A, Giordana MT, et al. Histologic prognostic factors in ependymoma. Childs Nerv Syst 1991;7:177-182.

3 Pollack IF, Gerszten PC, Martinez AJ, et al. Intracranial ependymomas of childhood: long-term outcome and prognostic factors. Neurosurgery 1995;37:655-667.

4 Ernestus R-I, Schroder R, Stutzer H, et al. The clinical and prognostic relevance of grading in intracranial ependymomas. Br J Neurosurg 1997;11:421-428.

5 Robertson PL, Zeltzer PM, Boyett JM, et al. Survival and prognostic factors following radiation therapy and chemotherapy for ependymomas in children: a report of the Children's Cancer Group. J Neurosurg 1998;88: 695-703.

6 Figarella-Branger D, Civatte M, Bouvier-Labit C, et al. Prognostic factors in intracranial ependymomas in children. J Neurosurg 2000;93:605-613.

7 Mansur DB, Michalski JM, Wahab SH, et al. Long-term results of surgery and post-operative radiation therapy in the curative management of intracranial ependymoma. Int J Radiat Oncol Biol Phys 2002;54:204-205.

8 Rajaram V, Leuthardt EC, Singh PK, et al. 9p21 and $13 q 14$ dosages in ependymomas. A clinicopathologic study of 101 cases. Mod Pathol 2004;17:9-14.

9 Ransom DT, Ritland SR, Kimmel DW, et al. Cytogenetic and loss of heterozygosity studies in ependymomas, pilocytic astrocytomas, and oligodendrogliomas. Genes Chrom Cancer 1992;5:348-356.

10 Mazewski C, Soukup S, Ballard E, et al. Karyotype studies in 18 ependymomas with literature review of 107 cases. Cancer Genet Cytogenet 1999;113:1-8.

11 Zheng P, Pang JC, Hui AB, et al. Comparative genomic hybridization detects losses of chromosomes 22 and 16 as the most common recurrent genetic alterations in primary ependymomas. Cancer Genet Cytogenet 2000;122:18-25.

12 Rubio M-P, Correa KM, Ramesh V, et al. Analysis of the neurofibromatosis 2 gene in human ependymomas and astrocytomas. Cancer Res 1994;54:45-47.

13 Gutmann DH, Giordano MJ, Fishback BS, et al. Loss of merlin expression in sporadic meningiomas, ependymomas and schwannomas. Neurology 1997;49: 267-270.

14 Ebert C, von Haken M, Meyer-Puttlitz B, et al. Molecular genetic analysis of ependymal tumors. NF2 mutations and chromosome 22q loss occur preferentially in intramedullary spinal ependymomas. Am J Pathol 1999;155:627-632. 
15 Lamszus K, Lachenmayer L, Heinemann U, et al. Molecular genetic alterations on chromosomes 11 and 22 in ependymomas. Int J Cancer 2001;91:803-808.

16 Singh PK, Gutmann DH, Fuller CE, et al. Differential involvement of protein 4.1 family members DAL1 and NF2 in intracranial and intraspinal ependymomas. Mod Pathol 2002;15:526-531.

17 Gutmann DH. The neurofibromatoses: when less is more. Hum Mol Genet 2001;10:747-755.

18 Louvet-Vallee S. ERM proteins: from cellular architecture to cell signaling. Biol Cell 2001;92:305-316.

19 Reardon DA, Entrekin RE, Sublett J, et al. Chromosome arm $6 q$ loss is the most common recurrent autosomal alteration detected in primary pediatric ependymoma. Genes Chromosomes Cancer 1999;24:230-237.

20 Tong CY-K, Zheng P-P, Pang JC-S, et al. Identification of novel regions of allelic loss in ependymomas by high-resolution allelotyping with 384 microsatellite markers. J Neurosurg 2001;95:9-14.

21 Scheil S, Bruderlein S, Eicker M, et al. Low frequency of chromosomal imbalances in anaplastic ependymomas as detected by comparative genomic hybridization. Brain Pathol 2001;11:133-143.

22 Parra M, Gascard P, Walensky LD, et al. Cloning and characterization of 4.1G (EPB41L2), a new member of the skeletal protein 4.1 (EPB41) gene family. Genomics 1998;49:298-306.
23 Scott C, Keating L, Bellamy M, et al. Protein 4.1 in forebrain postsynaptic density preparations. Enrichment of 4.1 gene products and detection of $4.1 \mathrm{R}$ binding proteins. Eur J Biochem 2001;268:10841094.

24 Gutmann DH, Donahoe J, Perry A, et al. Loss of DAL-1, a protein 4.1-related tumor suppressor, is an important early event in the pathogenesis of meningioma. Hum Mol Genet 2000;9:1495-1500.

25 Perry A, Cai DX, Scheithauer BW, et al. Merlin, DAL-1, and progesterone receptor expression in clinicopathologic subsets of meningioma: A correlative immunohistochemical study of 175 cases. J Neuropathol Exp Neurol 2000;59:872-879.

26 Perry A, Giannini C, Raghavan R, et al. Aggressive phenotypic and genotypic features in pediatric and NF2-associated meningiomas: A clinicopathologic study of 53 cases. J Neuropathol Exp Neurol 2001;60: 994-1003.

27 Robb VA, Li W, Gascard P, et al. Identification of a third protein 4.1 tumor suppressor, protein $4.1 \mathrm{R}$, in meningioma pathogenesis. Neurobiol Dis 2003;13: 191-202.

28 Korshunov A, Neben K, Wrobel G, et al. Gene expression patterns in ependymomas correlate with tumor location, grade, and patient age. Am J Pathol 2003;163:1721-1727. 